\title{
DELETION IN MOVIE SUBTITLING
}

\author{
Agus Darma Yoga Pratama \\ Universitas Warmadewa \\ agusdarmayoga85@yahoo.com
}

Received: 11-04-2018

Revised: $16-04-2018$

Accepted: $31-04-2018$

\begin{abstract}
Abstrak
Deletion in movie subtitling is a common practice due to limited space and time for subtitles to appear at the bottom of the screen. The limits are in terms of time for the subtitles to appear and be read by viewers and the number of characters to be shown on screen. Therefore, deletion is a strategy used especially for summarizing meaning or information from long dialogues. This is interesting because deletion should be implemented without deleting meanings or important information contained within the dialogues. Deletion is also considered to be used because viewers don't want to read long texts, as they are more focused on the scenes. This research is conducted to study types of deletion applied in movie subtitling and the impacts on delivering meanings to viewers. This research focuses on two movies, i.e. an adult action movie titled 13 Hours: The Secret Soldiers of Benghazi (2016) and a children animated movie titled Ice Age 5: Collision Course, in which English is the source language and Indonesian is the target language. These two movies are selected to compare deletion applied on action movies for adults and movies for children. This research applies deletion theory by Karamitroglou (1997) that summarizes deletion types in movie subtitling, such as functional expressions that don't contain semantic aspects, cumulative adjectives, and responsive expressions. Those three types of deletion don't interfere with delivery of meaning to viewers because they are supported by other aspects, such as dialogues, images, and music. The results of this research show that some taboo expressions are found in the adult action movie, whereas exclamations are found more in the animated movie. This is in line with the types of the movies, so selection of utterances for the subtitles is made according to the viewers' age. Some of the expressions are translated, while some other are not. This is due to technical aspects related to the number of characters that can be shown for each line of the subtitles. The translated expressions are responsive ones, like oh, fuck that, whoa, watch out, come on, all right, and yeah as well as cumulative adjectives, like $a$ fucking massive heavy force. The types of expressions that are not translated are responsive utterances like Ew in the animated movie Ice Age 5, expressions that indicate additional information like (MEN ARGUING), (GUNSHOT), (LAUGHS) in the action movie 13 Hours, and expressions for additional information like (SCREAMING) and (GRUNTING) in Ice Age 5.The translated and untranslated expressions are functional expressions that don't contain semantic meaning, like well in both movies.
\end{abstract}

Keywords: translation, deletion, expressions, strategy.

\section{INTRODUCTION}

Movie translation can be divided into two types: dubbing and subtitling. This research focuses on subtitling because it is more commonly used on foreign movies in Indonesia compared to dubbing. However, subtitling has its limitations in terms of delivering meaning, since there are some technical things that have to be applied, such as time limit for texts to appear on screen, limited number of characters that can be displayed, fonts, color, and texts position. Nevertheless, subtitling remains interesting as a topic to study. This is because the meaning in a movie can be delivered not only through subtitles that appear at the bottom of the screen. This statement is supported by Baker (1998) that says in a movie, meaning is delivered by combining four semiotic compositions, i.e. dialogues, music, subtitles, and images. Therefore, tehnical limitation does not interfere with delivery of meaning in a movie. Movie subtitlers must be able to select a strategy to translate the source language into the target language in a movie, while taking the technical limitation into consideration. Amongst all existing strategies, deletion is the most feasible. Karamitroglou (1997) states that there are some types of deletion that can be applied in movies subtitling, like deletion of expressions that don't contain semantic meaning, such as functional, cumulative adjectives or adverbial, and responsive expressions. Functional expressions are utterances like you know, well, and I say. These expressions often appear when someone tries to continue what is being said. Cumulative adjectives are utterances like great big, super extra, and teeny weeny. The first word of an expression that combines adjectives or double adverbs can be put together into a single word, like huge, extremely, tiny. Responsive expressions are utterances like yes, no, ok, please, thanks, thank you, and sorry. These expressions are commonly used in daily conversations, so they can be omitted. However, when responsive expressions are used in slangs, like yup, nup, oke, and tha, they cannot be understood. Thus, they must be written in the subtitles. Two movies are used in this research: 13 Hours: Secret Soldiers of Benghazi and Ice Age 5: Collision Course. 13 Hours: The Secret Soldiers of Benghazi is a movie about an attack to the US Embassy in Libya, while Ice Age 5: Collision Course is a story about Manny and his friends who were trapped in an apocalyptic disaster or doomsday caused by cosmic events. Both movies are used as the data for this research and to identify differences of deletion strategy between an action movie for adults and an animated movie for children.

\section{METHOD}

This research is qualitative descriptive, in which it uses descriptive data in the form of written or verbal words uttered by people being observed. This approach is directed to the background and the 
people as a whole (Bog and Taylor: 1975). The research data is subtitles from the movies 13 Hours: Secret Soldiers of Benghazi and Ice Age 5: Collision Course, in which English is the source language and Indonesian is the target language. The data is collected by using aegis sub, an app widely used to create and edit movies subtitles, so the researcher can easily pull the English and Indonesian texts as well as the timing for the texts to appear on screen. Therefore, the method of listen-and-note is not needed. The data is collected and grouped into one category, i.e. expressions that don't contain semantic meaning. The grouped expressions are then analyzed

\begin{tabular}{c}
\hline English \\
\hline 40
\end{tabular}

00:05:20,354 --> 00:05:21,853

Oh, come on.

She's mad at me, she's not mad at you.

80

00:06:54,148 --> 00:06:55,847

Fuck that.

373

00:19:58,298 --> 00:19:59,298

Whoa, whoa, whoa...

388

00:20:51,784 --> 00:20:52,784

Watch out!

563

00:29:04,510 --> 00:29:06,343

Come on.

2217

02:05:48,975 --> 02:05:51,109

A fucking massive heavy force.

The expressions in the above data are responsive and cumulative adjective. Responsive expressions identified are: oh, come on, found in the English texts $(40,563)$ and translated into Indonesian (40, 533). The number of characters for each subtitle text is small, i.e. 12 characters in the English text (40) oh, come on and 10 characters in the Indonesian text (40) oh, ayolah. The number of English characters (563) for come on is 8 and the Indonesian subtitle (533) ayolah 7 characters. The appearance of these responsive expressions does not exceed the maximum number of characters per line, i.e. 38 or 40 , so they are translated. However, these can be deleted or not translated since they do not contain significant semantic meaning. The expression fuck that (80) is translated as sialan in Indonesian (74). The expression fuck that conveys annoyance, impatience, and insults. These words are considered slang and taboo (Oxford: 2010). This expression appears because 13 Hours: Secret Soldiers of Benghazi is an action movie for adults, so the use of slangs and taboos are apparent. This expression is translated because it only contains small number of characters: 10 characters in English (80) fuck that and 7 characters in Indonesian (74) sialan. Anger, using deletion theory related to delivery of meaning through four semiotic aspects in movies.

\section{RESULTS AND DISCUSSION}

The following is the discussion on translations of functional, cumulative adjectives, and responsive expressions in the movie 13 Hours: Secret Soldiers of Benghazi and Ice Age 5: Collision Course. Some of those expressions are translated while some others are not.

A. Translated expressions

13 Hours: Secret Soldiers of Benghazi 


\section{RETORIKA: Jurnal Ilmu Bahasa , Vol. 4, No. 1 April 2018, Page 88}

contain significant semantic meaning. Some cumulative adjectives expressions are identified, like a fucking massive heavy force in the English text that is translated into sebuah angkatan bersenjata lengkap massif in Indonesian (2059). The strategy to translate cumulative adjectives expressions above is borrowing; the word massive is translated as masif because the meaning in the context of the movie is a massive heavy force. Nevertheless, the word lengkap is sufficient even without the word masif because the scene shown to the viewers is of a massive force.

The movie Ice Age 5: Collision Course

\begin{tabular}{cc}
\hline English & Indonesian \\
\hline 221 & 108 \\
$00: 10: 57,920->00: 10: 59,239$ & $00: 10: 55,916-->00: 10: 58,798$ \\
Yeah, women. & Wanita. \\
& Ya, wanita. \\
256 & 132 \\
$00: 12: 11,800->00: 12: 13,597$ & \\
Come on. & $00: 12: 11,432$--> $00: 12: 13,638$ \\
Let's get you cleaned up. & Ayo, kita bersihkan dirimu. \\
862 & \\
& \\
$00: 39: 41,280-->00: 39: 42,679$ & 489 \\
All right, kids. & $00: 39: 41,150-->00: 39: 42,735$ \\
\end{tabular}

In Ice Age 5: Collision Course, only responsive expressions are identified, they are: yeah in the English text (221) which is translated as $y a$ in Indonesian (108), come on in English (256) is translated as ayo in Indonesian (132), all right in English (862) is translated as baiklah in Indonesian (489). These three expressions are translated because of the small number of characters per line, i.e. not more than 38 or 40 characters. They also don't contain significant semantic meaning, so depending on the context and number of characters allowed per line, the subtitler may choose whether to translate them or not.

B. Untranslated expressions Movie 13 Hours: Secret Soldiers of Benghazi

\begin{tabular}{cc} 
English & Indonesian \\
\hline 53 & \\
$00: 05: 52,953$--> 00:05:54,419 & \\
(MEN ARGUING) & - \\
4 & - \\
$00: 01: 24,652-->00: 01: 25,652$ & \\
$($ GUNSHOT) & - \\
36 & \\
$00: 05: 07,875$-->00:05:09,641 & \\
(LAUGHS) & \\
\hline
\end{tabular}

Untranslated expressions in 13 Hours: Secret Soldiers of Benghazi are those containing additional information, like (MEN ARGUING), (GUNSHOT), and (LAUGHS). Each appearing text is only additional information for the viewers during fighting, shootings, and laughing scenes. The additional information is not translated into the target language because the meaning is already conveyed through images and sound effects. During fights or arguments, meaning is delivered through scenes and sounds of people fighting or arguing; in shooting scenes, meaning is delivered through images and sounds of gunshots; and in laughing scenes, meaning is already delivered in images and sounds of laughters. This is the appropriate strategy to be used by the subtitler, since those three aditional piece of information don't contain significant semantic meaning in the movie.

The movie Ice Age 5: Collision Course 


\begin{tabular}{cc}
\hline English & Indonesian \\
\hline 41 & \\
$\begin{array}{c}00: 03: 19,880-->00: 03: 20,880 \\
\text { (SCREAMING) }\end{array}$ & \\
50 & 125 \\
$00: 04: 04,520-->00: 04: 05,839$ & \\
$($ GRUNTING) & $00: 11: 44,570-->00: 11: 47,250$ \\
243 & Napasmubau. \\
$00: 11: 45,200-->00: 11: 46,633$ \\
Ew! Your breath is awful.
\end{tabular}

Untranslated expressions in Ice Age 5: Collision Course are those containing additional information and responsive expressions. The expressions that contain additional information are (SCREAMING) and (GRUNTING) in the English texts number (41) and (50). Both expressions are not translated into Indonesian as they do not contain semantic meaning. Although (SCREAMING) is not translated, the meaning is conveyed through images and sound effects. This also applies to (GRUNTING). The responsive expression $E w$ in English (243) is not translated because it doesn't contain significant semantic meaning. All deleted expressions do not affect the delivery of meaning to the viewers, because there are four semiotic aspects in movies that convey meaning concurrently: dialogues, subtitles, music, and images.

C. Translated and untranslated expressions Movie 13 Hours: Secret Soldiers of Benghazi

\begin{tabular}{cc}
\hline English & Indonesian \\
\hline 375 & 352 \\
$00: 20: 11,344-->00: 20: 13,344$ & $00: 20: 11,343-->00: 20: 13,344$ \\
Well, this is my 12 th. & Nah, ini tur ku yang ke 12. \\
& \\
425 & 401 \\
$00: 22: 22,041-->00: 22: 23,708$ & $00: 22: 22,041-->00: 22: 23,708$ \\
JACK: Well, & Kau akan pulang. \\
you'll be home. & \\
& \\
522 & 497 \\
$00: 26: 27,954-->00: 26: 29,594$ & Well, that's \\
heartwarming. & Itu menghangatkan hati. \\
\hline
\end{tabular}

Functional expression well that doesn't contain semantic meaning in the subtitles of 13 Hours: Secret Soldiers of Benghazi is translated as nah in Indonesian (352) while in some other parts it's not translated $(401,497)$. Translation or deletion of functional expressions can be applied depending on the number of characters in the subtitles as well as the context. In the case mentioned above, the subtitle text is translated and the number of characters is below the maximum limit, i.e. 38 or 40 . Moreover, it's translated because a context is required to emphasize certain information, even if the functional expression does not contain semantic meaning. Deletion of functional expressions is also applied in short subtitles in unnecessary contexts.

The movie Ice Age 5: Collision Course

\begin{tabular}{cc}
\hline English & Indonesian \\
\hline 231 & 116 \\
$00: 11: 19,520-->00: 11: 21,078$ & $00: 11: 19,074-->00: 11: 22,135$ \\
Well, Ellie giggled. & Tapi Ellie tertawa geli \\
232 & Lalu dia bergoyang-goyang. \\
$00: 11: 21,280-->00: 11: 22,599$ & 335 \\
And then she wiggled. & $00: 29: 39,149$--> 00:29:42,034 \\
624 & Buck sudah menyelamatkan \\
00:29:39,560 --> 00:29:42,074 & Hidup kita sebelumnya, 'kan?- \\
Well, Buck has saved & \\
our lives before, right? & \\
\hline \multicolumn{2}{c}{ Copyright $\odot$ 2018, RETORIKA: Jurnal Ilmu Bahasa } \\
\hline $\begin{array}{c}\text { Please cite this article as: Pratama. A. D. Y. 2018. Deletion in Movie Subtitiling. RETORIKA: Jurnal Ilmu Bahasa. 4. (1) } \\
\text { DOI: http://dx.doi.org/10.22225/jr.4.1.636.86-90 }\end{array}$
\end{tabular}




\section{RETORIKA: Jurnal Ilmu Bahasa , Vol. 4, No. 1 April 2018, Page 90}

The functional expression well is also found in Ice Age 5: Collision Course. It is apparent that well is both deleted and translated from English to Indonesian. Well in the English text (231) is translated into tapi (116), while the English translation (624) is deleted in the Indonesian text (353). Translation of well as tapi is applied because the information being emphasized is related to the previous piece of information, while in fact, the functional expression of well doesn't contain semantic meaning. The translator chose to translate the expression based on the consideration of small number of characters.

\section{CONCLUSION}

Based on the conducted research, it is concluded that in the movies 13 Hours: Secret Soldiers of Benghazi and Ice Age 5: Collision Course, three types of expressions have been identified: functional expressions that don't contain semantic meaning, cumulative adjectives expressions, and responsive expressions. Some of those expressions are translated while some others are not; there's one expression that is both translated and not translated in some parts of the movies. The translated expressions are responsive ones, like oh, fuck that, whoa, watch out, come on, all right, and yeah as well as cumulative adjectives, like a fucking massive heavy force. The types of expressions that are not translated are responsive utterances like $E w$ in the animated movie Ice Age 5, expressions that indicate additional information like (MEN ARGUING), (GUNSHOT), (LAUGHS) in the action movie 13 Hours, and expressions for additional information like (SCREAMING) and (GRUNTING) in Ice Age 5.The translated and untranslated expressions are functional expressions that do not contain semantic meaning, like well in both movies. The decision to translate those expressions are made based on the number of characters per line and the contexts in the movies, while deletion is chosen to cut number of characters used per line and unnecessary semantic meaning.

\section{REFERENCES}

Baker, M. 1992. In Other Word: A Coursebook on Translation. London: Sage Publication

Baker, M. 1998. Routledge Encyclopedia of Translation Studies. London: Routledge.

Bogdan, R. dan Taylor, Steven. J. 1975. Introduction to Qualitative Research Methods. USA: A Wiley-Interscience Publication

Diaz Cintas, J. 2009. New Trends in Audiovisual Translation. Great Britain: Cromwell Press Group Ltd.

Diaz Cintas, J., Anderman, Gunilla. 2009. Audiovisual Translation-Language Transfer on Screen. Great Britain: Palgrave Macmillan.

Diaz Cintas, Jorge. 2008. The Didactics of Audiovisual Translation. Amsterdam: John Benjamins Publishing Company.

Ivarsson, J., and Carrol, M. 2008. Subtitling. Simrishamn.

Karamitroglou, F. 1997. A Proposed Set of Subtitling Standards in Europe. Manchester, UK. European Association for Studies in Screen Translation (ESIST).

Oxford Advanced Learner's Dictionary ( $8^{\text {th }}$ edition). 2010. Oxford: Oxford University Press. 